\title{
0417 USE OF DATA LINKAGE IN DEVELOPING INJURY SURVEILLANCE SYSTEM IN TANZANIA
}

Y M Kishashu*, A Franzblau, TRobins, G Smith Correspondence: Muhimbili University of Health and Allied Sciences, United Nations Road, P. O. Box 65015, Dar es Salaam, Tanzania

10.1136/ip.2010.029215.417

Background Injury is one of the leading causes of death and disability in developing countries (Krug, 1999). Data on the impact of injuries on society have been non-existent in most developing countries, a situation likely to account for slow recognition of injuries as a public health problem by decision and policy-makers (Mock, 1995). This study, which was conducted in Tanzania, sought to describe patterns of severe traumatic work-related injuries; identify their causes and risk factors; evaluate the quality of reporting and recording workrelated injuries and; identify strategies for their prevention and control in Tanzania and other developing countries.

Methods Data were collected through structured interviews with 1385 injury cases admitted in the largest trauma hospital in Tanzania from March 2007 to March 2008. Detailed information was collected after work-relatedness of a case was established. Information from interviews was linked with hospital records, workers compensation and police data.

Findings A total of 638 (46\%) injury cases were classified as work-related injuries, and majority were male-workers (93\%). Linkage identified $138(10 \%)$ cases that were initially not identified as work-related. Based on minimum injury dataset, workers compensation data source had the most comprehensive injury dataset followed by hospital data source.

Conclusions Systems in place for collecting and recording injury data, lack nationally agreed guidelines for defining, reporting and recording injury information among the injury data sources in Tanzania. Injury surveillance systems in lowincome countries such as Tanzania could be developed using data linkages.

\section{References}

Krug E. Injury: a leading cause of global burden of disease. World Health Organization, Geneva, 1999.

Mock CN, Adzotor K, Conklin E, et al. Admissions for injury at a rural hospital in Ghana: prospects for prevention. Am J Public Health 1995;85:927-31. 